- Review Article

\title{
Physical Inactivity, Sedentary Behavior and Chronic Diseases
}

\author{
Karimé González', Jorge Fuentes ${ }^{2,3}$, José Luis Márquez ${ }^{4, *}$ \\ 'Student of Master of Science in Kinesiology, Universidad Católica del Maule, Talca, Chile \\ ${ }^{2}$ Departament of Kinesiology, Faculty of Health Sciences, Universidad Católica del Maule, Talca, Chile \\ ${ }^{3}$ Rehab Med Faculty, University of Alberta, Edmonton, Canada \\ ${ }^{4}$ School of Kinesiology, Faculty of Medical Sciences, Universidad de Santiago de Chile, Santiago, Chile
}

\begin{abstract}
New research into physical activity suggests that it is no longer sufficient just to meet minimum levels recommended by health guidelines in order to reduce cardiovascular risk. Both physical inactivity and sedentary behavior have their own health hazards and need to be addressed separately, in order to explore their different deleterious mechanisms. The aim of this review was to define and to characterize both concepts, and their relationship with major non-communicable chronic diseases. A PubMed database search was undertaken, using the following key words: physical activity, physical inactivity, sedentarism, sedentary behavior, and non-communicable chronic disease. This literature review provides an updated view on physical inactivity and sedentary behavior, and reevaluates their prevalence and association with major non-communicable chronic disease.
\end{abstract}

Keywords: Exercise; Sedentary Lifestyle; Chronic Disease; Public Health 


\section{INTRODUCTION}

The terms 'physical activity,' 'exercise,' 'physical inactivity,' ‘sedentarism,' and 'sedentary behavior' have been defined and interpreted differently throughout history.

Caspersen et al. ${ }^{1)}$ defined 'physical activity' as any bodily movement produced by skeletal muscle that requires energy expenditure, and 'exercise', as a subset of physical activity. Exercise involves a planned, structured, and repeated behavior aimed to maintain or improve components of physical fitness. These definitions remain in popular use. ${ }^{2)}$

One method to estimate the intensity of physical activity more accurately is by applying the metabolic equivalent method (MET). One measure of MET corresponds to the level of energy expenditure while resting quietly. Thus, physical activity may be classified as of light-intensity (<3 METs), moderate-intensity (3-6 METs) and vigorous-intensity ( $>6$ METs) physical activity. ${ }^{3)}$

Currently, a variety of recommendations exists to meet the minimum requirement for physical activity. Most of these recommendations indicate that individuals need to engage in moderate or vigorous intensity physical activity for a certain amount of time per week. At least 30 minutes of moderate-intensity physical activity, five days per week, or 20 minutes of more intense physical activities, 3 days per week, is recommended, for example. ${ }^{4,5)}$ The World Health Organization $^{2)}$ recommends that adults aged between 18 and 64 years should accumulate at least 150 minutes of moderate-intensity aerobic physical activity throughout the week, or undertake at least 75 minutes of vigorous-intensity aerobic physical activity throughout the week, or perform a combination of both forms of physical activity.

The use of the terms 'physical inactivity,' 'sedentarism' and 'sedentary behavior' has been controversial and some authors have suggested that it is essential to refine their definitions. ${ }^{6,7)}$

One of the first attempts to address the emergence of a health crisis from a physical-inactivity perspective was Booth et al., ${ }^{8)}$ who introduced an evolutionary explanation related to thrifty genes for an unhealthy sedentary population. Hamilton et al..$^{9)}$ reiterated that sedentary behavior involves all activities with low levels of metabolic energy expenditure. They highlighted 'too much sitting' as an important sedentary behavior leading to differing health hazards on metabolism, in relation to the lack of exercise. ${ }^{9,10)}$ Ten years after Booth's article, a call for scientists to explore the consequences of sedentary behavior, as an independent metabolic risk factor, was still being made. ${ }^{10,11)}$

An accurate classification of subjects, according to their total daily activities, is essential. This can be illustrated by objectively measuring physical activity. Pate et al. ${ }^{7)}$ compared accelerometer data from two subjects with different patterns of physical activity. First, they evaluated subject A, who did not meet the recommended levels of physical activity, but was engaged in low-intensity physical activity for $75 \%$ of his day, with $25 \%$ of his daily activity defined as sedentary behavior ( $\leq 1.5$ METs). Secondly, they evaluated subject B, who met the recommended levels of physical activity, but spent $70 \%$ of the day in sedentary behaviors. The authors concluded that subject A had a higher en- ergy expenditure level than subject B (26.3 METs and 23.6 METs, respectively) despite the latter being normally considered as 'active' by most studies. ${ }^{7}$

The development of sedentarism as a research field has been complex, since two working definitions currently exist, namely one definition used by those studying the effects of accumulating sedentary behaviors (mainly reported within biology and health literature); and another definition used by those who define 'sedentary behavior' as not engaging in minimum levels of physical activity (mainly reported within sports and exercise literature).

Aware of inconsistencies in the terminology, the Sedentary Behavior Research Network (SBRN) proposed, in 2012, a definition of sedentary behavior as any waking behavior with an energy expenditure of $\leq 1.5$ METs, while in a sitting or reclining posture. The term 'physical inactivity' was described as performing insufficient amounts of physical activity, that is, not meeting specified physical activity guidelines. ${ }^{12)}$ Despite some dissenting views, ${ }^{13)}$ an increasing number of researchers agree with the SBRN definition. ${ }^{14-16)}$

\section{THE PROBLEM OF NON-COMMUNICABLE CHRONIC DISEASES}

A chronic disease is slow in its progression and long-lasting. ${ }^{17)}$ The incidence of chronic disease has increased dramatically in the last century, and are considered to be an underestimated epidemic. ${ }^{8,18,19)}$ It is well known that obesity rates have risen dramatically over the last few years. In 2008, 34.3\% of men and women over 20 years of age had a body mass index (BMI) of $\geq 25 \mathrm{~kg} / \mathrm{m}^{2}$, globally. ${ }^{20)}$ It is estimated that, from 1980 to 2013, the prevalence of overweight and obese men and women has increased from $28.8 \%$ to $36.9 \%$, and from $29.8 \%$ to $38 \%$, respectively. Similarly, it was estimated in 1998 that the worldwide prevalence of diabetes in adults had been $4.0 \%$ in 1995, and that this was expected to rise by $5.4 \%$ by the year $2025 .{ }^{21)}$

Finally, in 1999, 34\% of all worldwide deaths in women and $28 \%$ in men were related to cardiovascular disease (CVD) ${ }^{22)}$ More recent data shows that one-third of worldwide deaths are due to CVD and this figure is expected to increase. ${ }^{23)}$

\section{THE PROBLEM OF PHYSICAL INACTIVITY}

In 2011, a study estimated that 1 in 5 people are insufficiently physically active. The sample recruited almost 300,000 individuals older than 15 years, from 76 different countries. ${ }^{24)}$ Booth et al. ${ }^{8)}$ suggested that the battle against chronic disease is inefficient due to an underestimation of the reality of the problem, and the emphasis is directed toward treatment strategies instead of preventative strategies.

Individuals engaging in light, moderate or vigorous physical activity had significantly lower risk for CVD mortality, regardless of their metabolic risk factors. ${ }^{25)}$ Conversely, physical inactivity resulted in a gain of abdominal and visceral fat. ${ }^{26)}$ In addition, physical inactivity has been associated with a higher risk of type 2 diabetes, regardless of age, sex, 
ethnicity, or BMI. ${ }^{27)}$ In fact, the two major risk factors associated with type 2 diabetes are obesity and physical inactivity. ${ }^{5}$ Evidence shows that the prevalence of diabetes is higher in obese, overweight and physically inactive individuals, and physical inactivity is independently related to an increased risk of each of these diseases. ${ }^{28,29)}$

In Canada, physical inactivity represents $3.7 \%$ of the overall health care costs. ${ }^{30}$ In China, more than $15 \%$ of both medical and non-medical costs are attributable to physical inactivity, per year. ${ }^{31)}$

The effects of small changes in physical inactivity habits are remarkable. In Australia, the benefits of reducing physical inactivity by $10 \%$ represent a cost saving of $0.19 \%$ of total annual health expenditure. ${ }^{32)}$ In people aged $\geq 70$ years, low-intensity physical activity at least once a week is associated with a reduced risk for type 2 diabetes, compared with those physically inactive. ${ }^{33)}$

Clearly physical inactivity is a determinant for health. However, recent evidence supports the fact that both physical inactivity and sedentary behavior contribute to the global burden of chronic disease, as discussed below.

\section{THE PROBLEM OF SEDENTARY BEHAVIOR}

Several studies have explored the relationship between diverse sedentary behaviors and CVD. For example, Warren et al. ${ }^{34)}$ found that men who reported being in a car for more than 10 hours per week had an $82 \%$ greater risk of CVD mortality compared to men who reported fewer than 4 hours per week. Also, it has been reported that one additional hour of sedentary activity increases the risk of being overweight (13\%) and developing high abdominal fat (26\%). ${ }^{35)}$

The effects of different leisure-time sedentary behaviors on obesity have also been studied. In a Canadian population study, the prevalence of obesity was significantly higher in people who watched television for more than 21 hours per week, and lower in people who watched television for fewer than 5 hours per week (from $25 \%$ to $14 \%$ in men and from $24 \%$ to $11 \%$ in women), regardless of leisure-time and physical activity. ${ }^{36)}$ An increase of 2 hours per day in watching television was related to a $14 \%$ higher risk of developing type 2 diabetes. Moreover, an increment of 2 hours per day in time spent seated at work was associated with a $7 \%$ increase in developing diabetes. ${ }^{37}$

Recently, the National Heart, Lung and Blood Institute, the National Institute on Aging, and the Office of Disease Prevention of the National Institutes of Health, assembled a panel of expert scientists to discuss relevant issues in the field of sedentary behavior and to identify research priorities. Discussion meetings were summarized into four areas; epidemiology, physiology, intervention strategies, and research strategies about sedentary behavior. ${ }^{38-42)}$ This demonstrates a growing institutional scientific recognition of this topic.

\section{CONCLUSION}

Current trends in the study of physical activity and inactivity merit close attention. There is growing evidence to suggest that there is a po- tential risk threshold for health, related to the degree of activity or inactivity. On the one hand, there is an optimal amount of time spent in physical activities to promote favorable health effects, while on the other hand, there is an optimal amount of time spent in sedentary behavior, beyond which developing chronic disease is more likely. The clear message is that to be physically active is not enough, but one also needs to avoid too much time spent in sedentary behaviors.

A more complete physiological understanding of the implications for health of the physical activity continuum is urgently needed. Both physical inactivity and sedentary behavior contribute to the burden of chronic disease. It has been proposed that future investigation designs should attempt to include examples of both sedentary conditions and physically inactive conditions, in order to establish a global perspective about the specific contribution of each one to chronic disease. ${ }^{42)}$

To achieve this goal, methods should include both subjective and objective measurement tools. Objective measurements, such as accelerometers, provide more accurate information about patterns of physical activity, thereby reducing measurement error. However, objective measurements cannot account for the specific domain of sedentary behavior, such as watching television, playing video games, or being seated at work. ${ }^{39)}$ Therefore, a global assessment needs to incorporate self-report data from subjects in addition to objective measurements.

Future research needs a new approach to focus on the appropriate use of these assessment methods to gain a better understanding of the impact of sedentary behavior and physical inactivity for global population health. This is necessary because sedentary behavior and physical inactivity represent two different conditions with unique and differing underlying biological mechanisms. Once this new approach is applied, more effective intervention strategies can be proposed.

The primary interest of research studies has been centered on the positive health benefits of exercise as a gold standard medicine. Better understanding of the detrimental effects of both physical inactivity and sedentary behaviors can also assist in promoting positive health outcomes.

\section{CONFLICT OF INTEREST}

No potential conflict of interest relevant to this article was reported.

\section{REFERENCES}

1. Caspersen CJ, Powell KE, Christenson GM. Physical activity, exercise, and physical fitness: definitions and distinctions for health-related research. Public Health Rep 1985;100:126-31.

2. World Health Organization. Global recommendations on physical activity for health. Geneva: World Health Organization; 2010.

3. Pate RR, Pratt M, Blair SN, Haskell WL, Macera CA, Bouchard C, et al. Physical activity and public health: a recommendation from the Centers for Disease Control and Prevention and the American College of Sports Medicine. JAMA 1995;273:402-7.

4. Haskell WL, Lee IM, Pate RR, Powell KE, Blair SN, Franklin BA, et al. 
Physical activity and public health: updated recommendation for adults from the American College of Sports Medicine and the American Heart Association. Med Sci Sports Exerc 2007;39:1423-34.

5. Knight JA. Physical inactivity: associated diseases and disorders. Ann Clin Lab Sci 2012;42:320-37.

6. Yates T, Wilmot EG, Davies MJ, Gorely T, Edwardson C, Biddle S, et al. Sedentary behavior: what's in a definition? Am J Prev Med 2011; 40:e33-4.

7. Pate RR, O'Neill JR, Lobelo F. The evolving definition of "sedentary". Exerc Sport Sci Rev 2008;36:173-8.

8. Booth FW, Gordon SE, Carlson CJ, Hamilton MT. Waging war on modern chronic diseases: primary prevention through exercise biology. J Appl Physiol (1985) 2000;88:774-87.

9. Hamilton MT, Healy GN, Dunstan DW, Zderic TW, Owen N. Too little exercise and too much sitting: inactivity physiology and the need for new recommendations on sedentary behavior. Curr Cardiovasc Risk Rep 2008;2:292-8.

10. Owen N, Healy GN, Matthews CE, Dunstan DW. Too much sitting: the population health science of sedentary behavior. Exerc Sport Sci Rev 2010;38:105-13.

11. Katzmarzyk PT. Physical activity, sedentary behavior, and health: paradigm paralysis or paradigm shift? Diabetes 2010;59:2717-25.

12. Sedentary Behaviour Research Network. Letter to the editor: standardized use of the terms "sedentary" and "sedentary behaviours". Appl Physiol Nutr Metab 2012;37:540-2.

13. Viir R, Veraksits A. Discussion of "letter to the editor: standardized use of the terms sedentary and sedentary behaviours": sitting and reclining are different states. Appl Physiol Nutr Metab 2012;37:1256.

14. Dogra S, Stathokostas L. Sedentary behavior and physical activity are independent predictors of successful aging in middle-aged and older adults. J Aging Res 2012;2012:190654.

15. Kim J, Tanabe K, Yokoyama N, Zempo H, Kuno S. Objectively measured light-intensity lifestyle activity and sedentary time are independently associated with metabolic syndrome: a cross-sectional study of Japanese adults. Int J Behav Nutr Phys Act 2013;10:30.

16. Spittaels H, Van Cauwenberghe E, Verbestel V, De Meester F, Van Dyck $\mathrm{D}$, Verloigne $\mathrm{M}$, et al. Objectively measured sedentary time and physical activity time across the lifespan: a cross-sectional study in four age groups. Int J Behav Nutr Phys Act 2012;9:149.

17. Hoffman C, Rice D, Sung HY. Persons with chronic conditions: their prevalence and costs. JAMA 1996;276:1473-9.

18. Andersen K, Gudnason V. Chronic non-communicable diseases: a global epidemic of the 21st century. Laeknabladid 2012;98:591-5.

19. Strong K, Mathers C, Leeder S, Beaglehole R. Preventing chronic diseases: how many lives can we save? Lancet 2005;366:1578-82.

20. Finucane MM, Stevens GA, Cowan MJ, Danaei G, Lin JK, Paciorek CJ, et al. National, regional, and global trends in body-mass index since 1980: systematic analysis of health examination surveys and epidemiological studies with 960 country-years and $9 \cdot 1$ million participants. Lancet 2011;377:557-67.

21. King H, Aubert RE, Herman WH. Global burden of diabetes, 19952025: prevalence, numerical estimates, and projections. Diabetes Care 1998;21:1414-31.

22. Yusuf S, Reddy S, Ounpuu S, Anand S. Global burden of cardiovascular diseases: part I: general considerations, the epidemiologic transition, risk factors, and impact of urbanization. Circulation 2001;104:2746-53.

23. Gaziano TA. Economic burden and the cost-effectiveness of treatment of cardiovascular diseases in Africa. Heart 2008;94:140-4.

24. Dumith SC, Hallal PC, Reis RS, Kohl HW 3rd. Worldwide prevalence of physical inactivity and its association with human development index in 76 countries. Prev Med 2011;53:24-8.

25. Reddigan JI, Ardern CI, Riddell MC, Kuk JL. Relation of physical activity to cardiovascular disease mortality and the influence of cardiometabolic risk factors. Am J Cardiol 2011;108:1426-31.

26. Slentz CA, Aiken LB, Houmard JA, Bales CW, Johnson JL, Tanner CJ, et al. Inactivity, exercise, and visceral fat. STRRIDE: a randomized, controlled study of exercise intensity and amount. J Appl Physiol (1985) 2005;99:1613-8.

27. Admiraal WM, van Valkengoed IG, L de Munter JS, Stronks K, Hoekstra JB, Holleman F. The association of physical inactivity with type 2 diabetes among different ethnic groups. Diabet Med 2011;28:668-72.

28. Longo-Mbenza B, On'kin JB, Okwe AN, Kabangu NK, Fuele SM. Metabolic syndrome, aging, physical inactivity, and incidence of type 2 diabetes in general African population. Diab Vasc Dis Res 2010;7:28-39.

29. Sullivan PW, Morrato EH, Ghushchyan V, Wyatt HR, Hill JO. Obesity, inactivity, and the prevalence of diabetes and diabetes-related cardiovascular comorbidities in the U.S., 2000-2002. Diabetes Care 2005;28:1599-603.

30. Janssen I. Health care costs of physical inactivity in Canadian adults. Appl Physiol Nutr Metab 2012;37:803-6.

31. Zhang J, Chaaban J. The economic cost of physical inactivity in China. Prev Med 2013;56:75-8.

32. Cadilhac DA, Cumming TB, Sheppard L, Pearce DC, Carter R, Magnus A. The economic benefits of reducing physical inactivity: an Australian example. Int J Behav Nutr Phys Act 2011;8:99.

33. Demakakos P, Hamer M, Stamatakis E, Steptoe A. Low-intensity physical activity is associated with reduced risk of incident type 2 diabetes in older adults: evidence from the English Longitudinal Study of Ageing. Diabetologia 2010;53:1877-85.

34. Warren TY, Barry V, Hooker SP, Sui X, Church TS, Blair SN. Sedentary behaviors increase risk of cardiovascular disease mortality in men. Med Sci Sports Exerc 2010;42:879-85.

35. Byun W, Dowda M, Pate RR. Associations between screen-based sedentary behavior and cardiovascular disease risk factors in Korean youth. J Korean Med Sci 2012;27:388-94.

36. Shields M, Tremblay MS. Sedentary behaviour and obesity. Health Rep 2008;19:19-30.

37. Hu FB, Li TY, Colditz GA, Willett WC, Manson JE. Television watching and other sedentary behaviors in relation to risk of obesity and type 2 diabetes mellitus in women. JAMA 2003;289:1785-91.

38. Boyington J, Joseph L, Fielding R, Pate R. Sedentary behavior research priorities: NHLBI/NIA sedentary behavior workshop summary. Med Sci Sports Exerc 2015;47:1291-4.

39. Gibbs BB, Hergenroeder AL, Katzmarzyk PT, Lee IM, Jakicic JM. Definition, measurement, and health risks associated with sedentary behavior. Med Sci Sports Exerc 2015;47:1295-300.

40. Manini TM, Carr LJ, King AC, Marshall S, Robinson TN, Rejeski WJ. Interventions to reduce sedentary behavior. Med Sci Sports Exerc 2015;47:1306-10.

41. Rosenberg DE, Lee IM, Young DR, Prohaska TR, Owen N, Buchner 
DM. Novel strategies for sedentary behavior research. Med Sci Sports Exerc 2015;47:1311-5.

42. Thyfault JP, Du M, Kraus WE, Levine JA, Booth FW. Physiology of sed- entary behavior and its relationship to health outcomes. Med Sci Sports Exerc 2015;47:1301-5. 